\title{
Dialect, Class struggle and Immigration in The Lonely Londoners, Saturday Night and Sunday Morning and Room At the Top
}

\author{
*Dr. Ramandeep Mahal ,**Ms. Tanu Bura \\ *Assistant Professor, Department of Humanities and Social Sciences, Maharishi \\ Markandeshwar (Deemed to be University), Mullana- Ambala \\ **Research Scholar, Department of Humanities and Social Sciences, Maharishi \\ Markandeshwar (Deemed to be University), Mullana- Ambala
}

\begin{abstract}
This paper addresses a little piece of a lot more extensive undertaking looking at the connections between working class and migrant writing which will frame a piece of my thesis. I will discuss the employments of lingo, class struggle and interesting differences in these books from the 1950s - John Braine's Room At the Top (1957), Alan Sillitoe's Saturday Night and Sunday Morning (1958) and Sam Selvon's The Lonely Londoners (1956). I'll begin with reference to a novel from the very period that maintains a strategic distance from broad utilization of tongue, prior to going to how these creators use vernacular and standard English alongside one another, just as set against one another, prior to getting done with an endeavor to historicize their employments of lingo. English the most prevalent language of the world has evolved with times influenced by German about 30\%, Latin 30\%, French 25\%, Greek 5\% and other languages about 10\%. Surprisingly London alone has 300 other different languages spoken and they all influence add to the further development of Lingo and communication.
\end{abstract}

KEYWORDS: Extensive, Period, Broad, Vernacular and Standard.

\section{INTRODUCTION:}

Arthur Seaton, the novel's (Saturday Night and Sunday Morning) hero, drives a lovely one-dimensional presence. He works away at an impasse work in the nearby processing factory the entire week, then, at that point come the end of the week he's off out for a spot of drinking, relaxed sex, and thoughtless viciousness. In a particularly troubling climate, where openings for average working class are rare, this establishes a sort of endurance methodology for Arthur and endless other youthful ordinary men in post-war Britain. Hurling himself every week head-first into an existence of epicurean abundance is about the solitary way that Arthur can enhance the constant sadness that consumes his spirit consistently.

A valid statement of flight is a concise citation from John Braine's Room at the Top (1957), where upwardly-versatile storyteller thinks back to the manner in which he used to talk:

When I say that she suited me I use the word in the Yorkshire sense too, meaning pleased with, delighted about: Ah'm right suited wi' thee lass, was a statement I made entirely without facetiousness; it expressed something I couldn't say in any other language. 
The novel is composed only in standard English however the storyteller's plan of action here is to utilize the Yorkshire tongue of his childhood as a means to communicate any genuine profundity of feeling. This features a squeezing social worry of this period: 'As a result of the 1944 Education Act, an exceptional number of common individuals were entering language schools and colleges'. The aftermath of the Great War resulted in Government educational grants for young servicemen and the underprivileged, This implied more individuals from 'Ordinary Working Class' were entering human expressions and callings. As Dominic Shellard advises us, 'a very much figured phrasing was evidence positive of insight', it additionally took territorial vernaculars and class complements from the mouths of these grant young men and ladies. This resulted in upward Social passage into another class, rendering many, in Richard Hoggart's words, 'declassed', 'removed and restless'. Braine was a grant kid and the social climb of his hero is loaded with the tensions of a deficiency of class personality. Braine is normal of numerous authors of the period who were grant young men themselves as well as were into representative composing for another segment made out of likewise 'declassed' individuals. Braine's book is at last skeptical: alongside Standard English, the storyteller disguises the independence and getting a handle on desire that encapsulates the most noticeably terrible aspect of working class esteems.

While Braine's utilization of tongue is momentary, reverse looking and nostalgic, different writers in the period responded to the pre-greatness of Received Pronunciation all the more contentiously, affirming the worth of vernacular and setting it close by, just as against, Standard English. Alan Sillitoe was not a grant kid thus had not had his language of expression systematically dislodged by thorough instruction in Received Pronunciation. Expanding on the pre-war custom of average composition and following Robert Graves' recommendation to expound on his local Nottingham, Sillitoe set about making a vernacular arched mixture artistic maxim. This artistic lingo permitted Sillitoe to express, and stay consistent with, modern common life yet didn't nullify a far more extensive crowd. The first and third sections of the original's initial page exhibit Sillitoe's specialty and set up the dialogic connection among standard and regional registers which is so vital to the story universe of the content:

The rowdy gang of singers who sat at the scattered tables saw Arthur walk unsteadily to the head of the stairs, and though they must all have known that he was dead drunk, and seen the danger he would soon be in, no one attempted to talk to him and lead him back to his seat. With eleven pints and seven small gins playing hide-and-seek inside his stomach, he fell from the top-most stair to the bottom.

For it was Saturday night, the best and bingiest glad-time of the week, one of the fifty-two holidays in the slow-turning Big Wheel of the year, a violent preamble to a prostrate Sabbath. Piled-up passions were exploded on a Saturday night, and the effect of a week's monotonous graft in the factory was swilled out of your system in a burst of goodwill. You followed the motto 'be drunk and be happy', 
kept your crafty arms around female waists, and felt the beer going beneficially down into the elastic capacity of your guts.

Aside from the informal 'dead drunk' the initial section is written in extremely fundamental Standard English. The revelers as a noisy group succumb to the feeling that they have to break the monotony of their mundane existence by drowning in alcohol and making merry. So engrossed are they in this activity that no one attempts to help Arthur despite the fact that he is in peril due to his over indulgence.. Additionally also balanced by the self evident tone which recommends this as a normal weekend activity for all of the working classes. The third section sees a sensational change in style and tone, the composition moves from the person on foot Standard English of the initial passage towards a sort of half and half which utilizes the lively examples of average discourse and starts to mix components of standard and lingo English together. The impact is a synchronous presentation of average character that adjusts to the generalization of common individuals as careless pleasure seekers and a phonetic showing-off that puzzles bias against non-standard speakers. 'Bingiest happy time', 'gulped' and 'join' are markers of demotic discourse. The 'prelude to a prostrate Sabbath' and 'stacked up interests' 'detonated' play out a beautiful 'stacking up' of plosives while foregrounding a wide jargon and a simple and creative office for language. The joined expressions and percussive sonic redundancy duplicate the rhythms of average discourse and give the entry a hard, lilting, speedy music. The entry is additionally conveyed cheerfully on the authorial face: Sillitoe is burlesquing the back-slapping bonhomie of the cliché average local area. It performs common personality while subtly 'othering' a nonaverage per user - the immediate location accepts a partiality between the per user and the common scene being portrayed - Sillitoe is exhibiting his ability to innovatively join standard and demotic English, assembling the rhythmicality of lingo to make a fearless and particularly middle class artistic voice. Sillitoe's expressed point 'of attempting to depict customary individuals as [he] knew them, and so that they would perceive themselves' is accomplished here: they not just see their own discourse and climate put down on the page, they likewise see their unpredictable connection to the socially and socially unrivalled standard English in which they may have been instructed and with which they will be acquainted on some level.

This two-tone opening builds up a dialogic portrayal that envelops the Standard English all-knowing storyteller and what we will before long come to perceive as Arthur Seaton's voice. Where Walter Greenwood had tested the set up phonetic pecking order of text in Love on the Dole by giving definitive exchange to tongue talking characters, Sillitoe goes further, permitting particular semantic registers to seep into one another and it could be said to turn into a 'abstract vernacular'. The long-standing polarity between Standard English portrayal and exchange in the demotic is tested from the initial page and keeps on being separated as the content advances.

Comparable expanding vicinity between the consciousnesses of the storyteller and the hero describes The Lonely Londoners. Its opening likewise sets up a disjuncture, yet of an alternate kind: 
One grim winter evening, when it had a kind of un realness about London, with a fog sleeping restlessly over the city and the lights showing in the blur as if is not London at all but some strange place on another planet, Moses Aloetta hop on a number 46 bus at the corner of Chepstow Road and Westbourne Grove to go to Waterloo to meet a fellar who was coming from Trinidad on the boat-train.

When Moses sit down and pay his fare he take out a white handkerchief and blow his nose. The handkerchief turn black and Moses watch it and curse the fog. He wasn't in a good mood and the fog wasn't doing much to help the situation. He had was to get up from a nice warm bed and dress and come out in this nasty weather to go and meet a fellar he didn't even know.

Selvon conjures the 'high' abstract practice of London, repeating Dickens' Bleak House and T. S. Eliot's 'The Waste Land' in his initial section. This distinguished practice is ambiguously conjured by an account voice shorn of large numbers of the markers of Standard English. Once more, the musicality of the exposition is key to catching the lingo. Selvon's tongue portrayal is unobtrusive; he tries not to withdraw profoundly from Standard English orthography. His attention is mainly on the sentence structure and the sonic example he is attempting to catch:

I didn't use d-e for t-h-e; I feel t-h-e is fine with me. When I open a book, I look at a sentence, I look at the writing of it, and I say that's ok if the rhythm of the dialect is still there.

Susheila Nasta writes that

Selvon combines in his fiction elements of both Trinidadian and Standard English. What he maintains above all is an ear for the oral and rhythmic qualities of Trinidadian colloquial speech. But while he reproduces in some measure the speech patterns of the people, it is clearly an artificial form of the language adapted for a literary usage and which is accessible to an international as well as a local audience.

The replacement of 'Sillitoe' for 'Selvon' and 'Nottingham' or 'Northern' for 'Trinidadian' would make this section as relevant to Saturday Night and Sunday Morning for what it's worth to Selvon's work. The equivalent could be said to describe various common authors in and since the fifties, from Stan Barstow to James Kelman. The oral idea of the way of life Selvon and Sillitoe catch in their books is critical: following the abstract allusiveness of the original's opening, The Lonely Londoners subsides into an example of 'melody', 'oldtalk' and 'scene'. The Sunday morning get-togethers at Moses' cellar room where the 'young men' trade and decorate stories take on a practically strict importance 'like on the off chance that they going to chapel' or 'like in case is admission'. As Ashley Dawson brings up, these scenes mark Selvon's 'allocation of the construction of calypso melodies'. Selvon utilizes the strategies and qualities of an oral and melodic West Indian social structure to hybridize the novel and make it a fit medium to convey the experience of immigrants in the city. For Sillitoe, as well, the oral culture in which he grew up is integral to his way of 
thinking of portrayal: 'The best story, I have consistently felt, is an account verbally expressed resoundingly by an unskilled man'. Nasta additionally focuses towards the inborn duality of inventive composing secured in nearby, demotic culture: composing by and about the working people or Caribbean foreigners should look for a more extensive crowd than the specific segment which comprises its focal core interest. In this manner these creators should find some kind of harmony, manufacturing a trade off through 'a counterfeit type of the language adjusted for a scholarly use'. This double crowd is a typical worry for the two creators, however the similitude between their apparently altogether different negligible positions run a lot further than that. David Dabydeen, a Guyanese artist, was struck by the likenesses between Guyanese creole and the language of 'Sir Gawain and the Green Knight': 'I started to see [... ] the old split among north and south in Britain. The north/south separation is obviously suggestive of the split betwixt alleged Caribbean outskirts along with metropolitan focus of London'. In addition to the fact that writers resembled Sillitoe and Selvon composing from places of recorded semantic mistreatment, they were composing from similar to places of social and political periphery. E. P. Thompson's case that 'Britain is the last province of the British Empire' recommends the activities of these creators are in an unusual manner both semantically post-or against pioneer. Average composing regularly finds itself thusly, as on account of Tony Harrison's from the School of Eloquence, which centres around the etymological and chronicled measurements of class mistreatment and considers them to be straightforwardly identified with expansionism. Cairns Craig traces the phonetic order that verifiably established the class framework:

It is not by our colour, of course, that we have stood to be recognised as incomplete within the British context, it is by the colour of our vowels: the rigidity of class speech in Britain, the development of Received Pronunciation as a means of class identity, is the direct response of a dominant cultural group faced by a society in which the outsiders are indistinguishable by colour.

Elsewhere, he makes the point that the use of dialect is a means of challenging this class-linguistic order:

Novels committed to the use of dialect necessarily involve themselves not only in dialogue - the speech of the demotic - and in the dialogic - in Bakhtin's sense of multiple voices within a text - but also in a dialectic, because the existence of two or more distinct linguistic contexts within the text presumes the existence of alternative value systems which those linguistic contexts express, and therefore of a dialectical process of debate and argument between those values.

All three Selvon, Braine and Sillitoe saddle the inventive capability of this persuasive cycle in their books. While Craig is correct that the 'presence' of particular etymological settings assumes elective worth frameworks, these writers now and again make show this contention. At the point when a columnist approaches Moses at Waterloo station where he is anticipating the appearance of one more 'boat-train' this resistance is organized with humour and poignancy: 
...a newspaper fellar come up to him and say, 'Excuse me sir, have you just arrived from Jamaica?',

... 'Would you like to tell me what conditions there are like?' The fellar take out notebook and pencil and look at Moses.

Now Moses don't know a damn thing about Jamaica - Moses come from Trinidad, which is a thousand miles from Jamaica, but the English people believe that everybody who come from the West Indies come from Jamaica.

'The situation is desperate,' Moses say, thinking fast, 'you know the big hurricane it had two weeks ago?'

'Yes?' the reporter say, for in truth it did have a hurricane in Jamaica....

'The hurricane blow off the roof.'

'But tell me, sir, why are so many Jamaicans immigrating to England?'

'Ah,' Moses say, that is a question to limit, that is what everybody trying to find out. They can't get work,' Moses say, warming up. 'And furthermore, let me give you my view of the situation in this country. We can't get no place to live, and we only getting the worst jobs it have $-\ldots$. '

The columnist is the solitary person whose discourse is standard English, aside from Harris, a Trinidadian who likes to play 'ladeda' and dress like a rich Englishman, and who is determinedly derided by the storyteller and his kindred workers. A Standard English peruser, having needed to arrange the new West Indian vernacular of the exchange and portrayal, unexpectedly perceives their own voice. That natural voice, when it shows up, is inconsiderate and sells out misrecognition - of Moses and of all West Indians as Jamaican originating from humiliating obliviousness. 'Where a very much formed style was evidence positive of knowledge', this is a provocative disruption of racial and etymological chains of importance and a mocking joke on the deterioration of the prevailing social foundations. Similarly as Sillitoe 'others' the careless, standard English envisioned per user, Selvon here advances to the socially minor and finds office there instead of with the middle. This is figured in Moses' untruth, which is incautious instead of naughty. At the rubbing point between the social foundation and recently arising average workers, the force relationship is profoundly conflicted. Moses will not present subtleties of the 'crude' settlements and rather investigates the false reverence of the supreme force whose guarantees of 'roads cleared with gold' were a deception for an encouragement to endure prejudice and social confinement as a trade-off for playing out the hardest and most minimal paid positions in British society. In an immediate experience among standard and tongue English, it is the Standard English speaker who is made to appear to be impolite and not well educated.

The solitary Standard English voice straightforwardly experienced in the debut novel of Sillitoe is that of Sam, an African officer companion of Arthur's cousin, who comes to remain with the Seatons for Christmas while in England for preparing. Sam 'quiet and wise', 'with a natural feeling of tact' is unmistakably better taught and more effective (he is a beautified fighter) than the average characters that structure the clever's core interest. His respectfulness and self-control go about as a contradiction to, and in fact a certain study of, the grievousness of the Seaton clan. Common tongue is set in logic resistance to 'prevalent' 
English that, essentially, is from outside the unbending pecking order of the British class framework.

Arthur gives a rankling evaluate of the foundation and without a doubt of socialists (who are generally addressed in average fiction as instructed individuals from the common who talk in Standard English) conveyed in Nottingham vernacular. At the point when an agreeable co-worker ridicules Arthur's apparently opposing suppositions on notion and socialism, he responds with a regional rant:

I said I was as good as anybody else in the world, din't I [...] And I meant it. Do you think if I won the football pools I'd gi' yo' a penny on it? Or gi' anybody else owt? Not likely. I'd keep it all mysen, except for seeing my family right. I'd buy 'em a house and set 'em up for life, but anybody else could whistle for it [...]. I like to hear 'em talk about Russia, about farms and power-stations they've got, because it's interestin', but when they say that when they get in government everybody's got to share and share alike, then that's another thing. I ain't a communist, I tell you. I like 'em though, because they're different from those big fat Tory bastards in parliament. And them Labour bleeders too [...]I voted communist at the last election[,]... \{he then goes on to relate how he only voted by taking his father's polling card.\}

Arthur's political and good position can be refined down to a compassion for 'the losin' side': the long shot, the persecuted, the truly underestimated greater part, are what he sees as 'his' side. The assertion, adjusted and put world on the map by the Arctic Monkeys, that 'whatever individuals think I am or say I am, that is the thing that I'm not' expresses Arthur's extreme independence: he will not be represented by anybody, no position or 'prevailing' language can talk his demotic pith. This takes us to the foundation of Selvon and Sillitoe's employments of lingo: in the post-war reorientation of British society, those at the edges requested to represent themselves.

The squeezing need to fashion another abstract language was a side effect of the occasions. The Education and Nationality Acts of 1944 and '48 prepared for a crucial change in the appearance of British society, permitting a more focal spot for the average workers and initiating the arranged post-war migration that brought laborers from the farthest reaches of the Empire to the pioneer community. Regarding the expanding pervasiveness of northern and common voices, David Lodge has depicts 'a seismic shift' which saw 'the removal of [the] abstract foundation by another age of authors who were average workers or lowerworking class in friendly foundation and recipients of open auxiliary with tertiary schooling undergoing 1944 Education Act'. 'Colonization in switch', as Louise Bennet depicted it, implied various types of English were progressively being spoken on British roads. The English expressed between the fronts of British books needed to change as well if it somehow managed to talk from, to and for the voting public that were progressively key to the country's thriving and advancement. The Suez emergency was meaningful of Britain's decay on the world stage, just as of how obsolete the presumptuous smugness of the British decision classes had become. Moses states while weeping over the bigotry frequently looked without 
anyone else and his kindred outsiders, 'Is we who drain to make the nation prosperous': he additionally discusses the 'public inclination' among foreigners and the regular workers. The characters in both these books play out the difficult work that makes Britain a prosperous society in the fifties and these artistic tongues are endeavors to cause the novel to address and for the individuals who drain, to make the original a structure fit for the portrayal of post-war average life.

\section{REFERENCES:}

1. BASU, BIMAN. "Linguistic and Libidinal Progressions in Sam Selvon's The Lonely Londoners." Mosaic: An Interdisciplinary Critical Journal, vol. 51, no. 2, 2018, pp. 75-90. JSTOR, www.jstor.org/stable/90021967. Accessed 7 Aug. 2021.

2. Graham MacPhee, Postwar British Literature and Postcolonial Studies (Edinburgh: Edinburgh University Press, 2011), p.56.

3. David Trotter, 'Colonial subjects', Critical Quarterly, 32.3 (Autumn 1990), 3-20 (p.3), emphasis original.

4. Laura Chrisman, 'The imperial unconscious? Representations of imperial discourse', Critical Quarterly 32 (Autumn 1990) 38-58 (p.38).

5. Sam Selvon, The Lonely Londoners (Essex: Longman, 2003), p.2.

6. Susheila Nasta (ed.), Writing across Worlds: Contemporary Writers Talk (London: Routledge, 2004), p.14.

7. Colin Wilson, The Angry Years: The Rise and Fall of the Angry Young Men (London: Robson, 2007)

8. Alan Sillitoe, Saturday Night and Sunday Morning (London: Flamingo, 1994), p.191.

9. Jonh Braine : Room At The Top : (Harmondsworth, Penguin Books, 1975) p.10 (All subsequent references are to this edition only and the page no. has been givne in parenthesis).

10. Malcolm Bradbury : The Modern British Novel (Harmondsworth, Penguin Books, 1994) P. 324 